\title{
Embedding comprehensive geriatric assessment in the emergency assessment unit: the impact of the COPE zone
}

\author{
Authors: Joanne K Taylor, ${ }^{A}$ Oliver S Gaillemin, ${ }^{B}$ Amy J Pearl, ${ }^{C}$ Sean Murphy ${ }^{D}$ and Jennifer Fox ${ }^{\mathrm{E}}$
}

\begin{abstract}
We introduced a geographically embedded frailty unit, the comprehensive older person's evaluation 'COPE' zone within our emergency assessment unit (EAU). We collated data for all medical patients over 75 years admitted non-electively for one month before and after this service change. Significantly more patients were seen by a geriatrician on the EAU earlier in their admission in 2014 (33.4 vs 19.3\%, p<0.001; 11 vs $20 \mathrm{~h}$, $\mathrm{p}<0.001)$. More patients had documented comprehensive geriatric assessment and discussion in a geriatrician multidisciplinary team meeting (relative risk (RR) 3.3, 95\% confidence interval (CI) 2.35-4.73, p<0.001; RR 3.6, 95\% CI 2.26-5.57, $p<0.001$, respectively). More patients with markers of frailty were discharged directly from EAU (42.2 vs $29.0 \%, p=0.006$ ) without increasing readmissions. Mean length of stay was reduced ( 9.5 vs 6.8 days, $p=0.02$ ). The introduction of the COPE zone has improved service delivery at the point of access for older people admitted to hospital.
\end{abstract}

KEYWORDS: Frailty unit, older people, acute medicine, comprehensive geriatric assessment, readmissions

\section{Introduction}

\section{Background}

There is a national drive to improve the care of older people admitted to hospital with an acute medical disorder in the $\mathrm{UK}^{1,2}$ (see www.frailsafe.org.uk/ and www.acutefrailtynetwork.org. uk). Best evidence-based care encompasses comprehensive geriatric assessment (CGA) and multidisciplinary team (MDT) input, leading to the development of 'interface geriatrics' on the acute medical take. ${ }^{3-6}$ Early input from geriatric services

Authors: A geriatric medicine specialist registrar, Department for Ageing and Complex Medicine, Salford Royal NHS Foundation Trust, Salford, UK; ${ }^{\mathrm{B}}$ consultant physician in acute medicine, Department of Acute Medicine, Salford Royal NHS Foundation Trust, Salford, UK; ${ }^{C}$ general practice trainee, Department of Acute Medicine, Salford Royal NHS Foundation Trust, Salford, UK; ${ }^{\text {D }}$ foundation training doctor, Department for Ageing and Complex Medicine, Salford Royal NHS Foundation Trust, Salford, UK; ${ }^{\mathrm{E}}$ Consultant in geriatric medicine, Department for Ageing and Complex Medicine, Salford Royal NHS Foundation Trust, Salford, UK has been shown to avoid unnecessary admissions, and prevent complications in hospital. ${ }^{7,8}$ While these benefits are globally acknowledged, challenges remain. High demand means it is not currently feasible for all older patients to receive 'gold standard' geriatrician-led MDT and CGA in the acute phase of their admission. For this reason various strategies have been used to identify older patients with markers of frailty whom would most benefit including in-reaching geriatric services and targeted assessments in the emergency department. ${ }^{7-9}$ The best way to integrate these interventions effectively into the current model of acute medical care remains an ongoing area of research. ${ }^{10,11}$ Identifying frail older patients objectively and quickly has not proved straightforward. The theoretic definition of frailty describes a 'clinically recognisable state of increased vulnerability, resulting from age-associated decline in reserve and function across multiple physiological systems such that the ability to cope with every day or acute stressors is compromised'. ${ }^{12}$ While most clinicians understand and accept this concept, there is a lack of consensus regarding the operational definition of frailty for use in everyday clinical practice. ${ }^{13}$ This makes it difficult to create validated basic screening tools, and current practice often relies on clinical discretion.

Acknowledging these challenges, our geriatric medicine and acute medicine teams took a novel approach to the reorganisation of services to create an acute frailty 'zone' within the emergency assessment unit (EAU). The comprehensive older person's evaluation 'COPE' zone was set up within our EAU in December 2013, to replace the pre-existing geriatrician in-reach service. Unlike other 'frailty units', the COPE zone was designed to work as an integrated part of the EAU through collaboration between geriatricians and acute physicians, allowing knowledge and resources to be shared. A set of four simple criteria were used to identify older patients at risk of frailty syndrome in the emergency department to facilitate the rapid and direct transfer of suitable patients for timely geriatrician-led CGA.

\section{The 'COPE' zone}

Twelve existing beds of the 55-bedded EAU were converted into the COPE zone. The model currently operates Monday to Friday, 8:30am - 5pm. Patients identified on referral to medicine as having one of the following criteria: falls, delirium, dementia or care home/intermediate care residents, are streamlined into this zone where possible. To prevent a 
'two-tier' system the service remained flexible, and frail older patients who were transferred to a non-COPE bed could also be referred and assessed. The COPE zone MDT members include a geriatrician, acute physician, nurse, physiotherapist, occupational therapist, social worker, mental health liaison nurse and pharmacist. The team meets for a twice-daily MDT meeting. Patients identified as potentially fit for direct discharge are kept on the COPE zone where possible; otherwise they are transferred to a geriatric medicine ward for ongoing inpatient care.

The COPE zone was introduced without increasing resources, rather reorganisation of existing staff. EAU acute physicians, junior doctors and nursing staff rotate through the zone, enabling sharing of skills and knowledge.

The primary aim of establishing the COPE zone was to reliably deliver high-quality care to older people admitted non-electively to hospital. This would include early access to geriatrician-led MDT input and CGA to more effectively coordinate treatment plans, optimise early discharge, and positively impact on length of stay and readmission rates.

\section{Study question}

Has the introduction of the COPE zone on our EAU improved the service delivered to older people admitted through the acute medical take?

\section{Method}

\section{Ethical issues}

COPE zone development and coordinated MDT working evolved iteratively. 'Plan, do, study, act' cycles were undertaken until the service became established in the form evaluated for this study. No changes to direct patient care occurred.

\section{Setting}

Salford Royal Foundation Trust (SRFT) is a large, urban teaching hospital serving a population of 240,000 people. ${ }^{14}$ Medical patients are admitted to EAU after being referred from either the emergency department or a general practitioner. SRFT uses an electronic patient record (EPR) system (Allscripts' Sunrise Clinical Manager).

\section{Change}

Prior to the introduction of the COPE zone, patients requiring geriatrician input were seen by a daily in-reaching service equivalent to one whole-time geriatrician (see Table 1). No other significant changes were implemented on the EAU during the study time frame.

\section{Change effect}

This study retrospectively compared all medical admissions of patients over 75 years admitted to our EAU in September 2013 and September 2014 (before and after COPE zone establishment). Objective outcome measures were: time until geriatrician review, rates of documented CGA and MDT input, direct EAU discharge rates, length of stay, discharge destination, rates of community follow-up, readmission rates

\section{Table 1. Summary of service changes.}

\section{September 2013}

$\begin{array}{ll}\text { Acute } & \begin{array}{l}\text { In-reaching model } \\ \text { (lone consultant }\end{array} \\ \text { seriatric } & \text { geriatrician) }\end{array}$

$\begin{array}{ll}\text { Collaboration } & \text { Independent } \\ \text { with EAU } & \text { working }\end{array}$

staff

\begin{tabular}{ll}
$\begin{array}{l}\text { Patient } \\
\text { identification }\end{array}$ & $\begin{array}{l}\text { Referrals from } \\
\text { acute physicians }\end{array}$ \\
MDT & $\begin{array}{l}\text { Worked } \\
\text { independently on } \\
\text { case by case basis }\end{array}$ \\
$\begin{array}{l}\text { Links with } \\
\text { community }\end{array}$ & Nil formal \\
\hline
\end{tabular}

\section{September 2014}

COPE zone embedded within the EAU with dedicated consultant geriatrician

Rotation of EAU staff through the COPE zone, including acute medical consultants, junior doctors and nursing staff

Streamlined into zone from the emergency department based on COPE criteria

Based on COPE zone with twice daily MDT meeting.

Direct referral pathway (developed iteratively) services

COPE = comprehensive older person's evaluation; $\mathrm{EAU}=$ emergency assessment unit; MDT = multidisciplinary team.

(7 and 30 day) and 30-day mortality (after discharge). CGA was defined as a multi-dimensional assessment encompassing all of the following domains: medical, mental health, functional capacity, social circumstances and environmental assessment. ${ }^{15}$ MDT input was defined as a documented meeting including at least two team members (excluding physicians) in addition to a geriatrician. Patients who died during their admission were included in all analysis (except length of stay, discharge and readmission data).

\section{Data management and analysis}

All patients were identified from the EPR using automated audit systems. Basic demographics and time-code data were pulled directly from the server onto Microsoft Excel for all data management and analysis. Three independent researchers (JKT, AJP and SM) manually checked all medical admissions of patients over 75 years to ensure correct coding and collated all additional information. A subgroup analysis of patients who had at least one of the four markers of frailty described above was performed. For simple bivariate analysis of categorical data, relative risk (RR) was used with 95\% confidence interval (CI). For other comparisons, student t-test or chi-squared test was used as appropriate. $\mathrm{p}<0.05$ was considered significant.

\section{Results}

Raw data pulled from the EPR server showed a total of 1,732 non-elective hospital admissions to SRFT in September 2013 and 1,843 in September 2014. Of these, 54\% (934) and 64\% $(1,170)$ respectively were admitted under the medical team. Patients over the age of 75 years made up $43 \%$ (398) of the acute medical take in 2013, and 35\% (413) in 2014. Table 2 shows the basic demographics and outcome data for these patients. 
Table 2. Baseline characteristics and outcome data.

Parameter

Part A: All medical admissions $>75$ years, $n$

\section{Patient characteristics}

Age, median (range)

Male, \% (n)

Mean non-elective hospital admissions in last 12 months

History of falls, \% ( $n$ )

Confusion/delirium, \% (n)

Dementia, \% (n)

Patient from a care home/IMC*, \% (n)

Any of four criteria above 'COPE criteria', \% (n)

\section{Outcome data}

Inpatient deaths, \% ( $\mathrm{n}$ )

Seen by geriatric medicine team, \% ( $n$ )

Mean time until geriatric review, days

Evidence of CGA, \% (n)

Evidence of MDT meeting, \% ( $n$ )

Mean length of stay, days

Direct discharge from EAU, \% (n)

New discharge to higher level of care, \% (n)

Follow up with community teams, \% (n)

7-day readmission rates, \% (n)

30-day readmission rates, $\%$ ( $n$ )

30-day mortality, \% (n)

Part B Patients with $\geq 1$ markers of frailty ${ }^{* *}, n$

Patient characteristics

Male, \% (n)

Mean non-elective hospital admissions in last 12 months

\section{Outcome data}

Inpatient deaths, \% ( $\mathrm{n}$ )

Seen by geriatric medicine team, \% (n)

Mean time until geriatric review, days

Evidence of CGA, \% ( $n$ )

Evidence of MDT meeting, \% ( $n$ )

Mean length of stay, days

Direct discharge from EAU, \% (n)

New discharge to higher level of care, \% (n)

Follow up with community teams, \% (n)

7-day readmission rates, $\%$ ( $n$ )

30-day readmission rates, $\%$ (n)

30-day mortality, \% (n)

\section{Pre-COPE}

(September 2013)

398

85 (75-101)

$32.7(130)$

1.40

$32.7(130)$

$19.8(79)$

$16.6(66)$

15.3 (61)

$54.5(217)$

$8.0(32)$

$19.3(77)$

0.85

8.8 (35)

$5.5(22)$

7.37

$35.2(140)$

$9.3(34)$

8.5 (31)

7.7 (28)

18.9 (69)

$6(22)$

217

$32.2(70)$

1.50

$7.4(16)$

$27.2(59)$

0.88

$13.4(29)$

7.8 (17)

9.53

$29.0(63)$

16.4 (33)

7.5 (15)

$9.0(18)$

$21.4(43)$

$8.0(16)$

\section{Post-COPE}

(September 2014)

413

$84(75-101)$

$39.5(163)$

1.44

$34.1(141)$

$20.3(84)$

$19.4(80)$

$18.4(76)$

$54.5(225)$

$9.0(37)$

$33.4(138)$

0.48

$29.3(121)$

$19.6(81)$

6.87

$43.3(179)$

$8.0(30)$

$12.5(47)$

$8.2(31)$

$18.1(68)$

4.6 (19)

225

$37.3(84)$

1.58

$10.7(24)$

47.6 (107)

0.49

$40.9(92)$

$29.3(66)$

6.76

$42.2(94)$

$10.0(20)$

$16.9(34)$

$9.0(18)$

$20.9(42)$

$3.0(6)$ $p$ value

0.04

0.56

0.66

0.86

0.30

0.24

0.99

RR, (95\% CI), p value

1.11 (0.71-1.75), 0.64

$1.72(1.36-2.20),<0.001$ $p<0.001$

3.33 (2.35-4.73), <0.001

3.55 (2.26-5.57), <0.001

$p=0.19$

1.23 (1.03-1.46), 0.02

0.86 (0.54-1.37), 0.53

$1.48(0.96-2.27), 0.08$

1.08 (0.66-1.76), 0.76

0.96 (0.71-1.30), 0.79

0.84 (0.46-1.53), 0.57

$p$ value

0.26

0.66

RR, (95\% CI), p value

1.45 (0.79-2.65), 0.23

$1.75(1.35-2.26),<0.001$

$\mathrm{p}=0.001$

$3.06(2.11-4.44),<0.001$

$3.74(2.27-6.17),<0.001$

$\mathrm{p}=0.02$

$1.44(1.11-1.86), 0.006$

$0.61(0.36-1.01), 0.06$

2.27 (1.28-4.03), 0.005

RR 1

0.98 (0.67-1.42), 0.9

$0.38(0.15-0.94), 0.04$

*Residential home/nursing home or intermediate care; **History of falls, dementia, delirium or from a care home/immediate care (as above). CGA = comprehensive geriatric assessment; $\mathrm{CI}=$ confidence interval; $\mathrm{COPE}=$ comprehensive older person's evaluation; $\mathrm{EAU}=$ emergency assessment unit; $\mathrm{MDT}=$ multidisciplinary team; $\mathrm{RR}=$ relative risk 
Both groups were well matched for age and COPE criteria comorbidities, however there was a significant difference in gender make up (33\% male in $2013,40 \%$ male in 2014 ). The reason for this is unclear.

Outcome analysis has demonstrated that in September 2014 (post-COPE), a significantly greater number of older patients were reviewed by a geriatrician on EAU (33.4 vs $19.3 \%$, RR $1.72,95 \%$ CI $1.36-2.20, \mathrm{p} \leq 0.001)$. Patients were reviewed significantly earlier into admission (mean 11 vs $20 \mathrm{~h}, \mathrm{p}<0.001$ ), and rates of CGA and MDT meetings were markedly higher (29.3 vs $8.8 \%$, RR 3.3, 95\% CI 2.35-4.73, $\mathrm{p}<0.001 ; 19.6$ vs $5.5 \%$, RR 3.6, 95\% CI 2.26-5.57, $\mathrm{p}<0.001$ respectively).

Rates of direct discharge from the EAU were slightly higher in 2014 ( 43.3 vs $35.2 \%$, RR 1.2, 95\% CI 1.03-1.46, $\mathrm{p}=0.02$ ). Mean length of stay on EAU was not increased after the introduction of the COPE zone (1.1 vs 1.0 days, $\mathrm{p}=0.24)$ indicating no detriment to patient flow on EAU. Overall mean length of stay for older patients in 2014 was slightly shorter (6.9 vs 7.4 days, $\mathrm{p}=0.19$ ) though this was not statistically significant. Readmission rates and 30-day mortality rates were not significantly different.

A geriatrician reviewed almost $50 \%$ of patients who met criteria for the COPE zone in 2014 on EAU. Rates of CGA and MDT were high (40.9 and 29.3\% respectively) and proportionately greater when isolating this subgroup of patients. Direct discharge rates were significantly higher without impacting on readmission rates (discharge rates 42.2 vs $29.0 \%, p=0.006$; 30 -day readmission rates 20.9 vs $21.4 \%$, $p$ $=0.9$ ). Mean length of stay was significantly shorter ( 6.8 vs 9.5 days, $\mathrm{p}=0.03$ ), and 30 -day mortality on discharge was less (3 vs $8 \%, \mathrm{p}=0.04)$.

We performed further analysis on the 2014 cohort data to compare outcomes for patients admitted to the COPE zone versus those who were not. This showed similar improved outcomes for those on the COPE zone with regard to direct discharge rates, readmission rates and 30-day mortality, but not length of stay. Patients with markers of frailty on the COPE zone who were discharged directly from EAU had similar EAU length of stay as those in non-COPE beds (mean length of stay 1.2 vs 1.1 days, $p=0.63$ ), and this was also the case for total length of stay for those requiring ward admission (12.4 vs 10.8 days, $\mathrm{p}=0.51$ ).

\section{Discussion}

\section{Summary}

Redesigning acute geriatric services at SRFT has focused valuable resources towards older adults admitted via the acute medical take. This change has resulted in greater access to early geriatrician-led MDT input and CGA. Impact on outcome measures has been generally positive, particularly for patients with markers of frailty. Rates of direct discharge home from EAU were greater without prolonging length of stay. This was achieved without increasing resources, and has not negatively impacted on patient flow or readmission rates.

\section{Local services}

The ever-increasing proportion of complex, frail patients onto the acute medical take fuelled the rationale for switching from a geriatrician in-reach service to an embedded frailty unit. Other proactive acute geriatric services in the UK have also shown an improvement in service delivery and outcomes compared with more traditional models. ${ }^{8,16}$ The evidence base is growing to support radical changes to the delivery of acute care in the UK, shifting resources in line with changing demographics and patient mix.

One of the main aims of the COPE zone was to improve efficiency, proactiveness and coordination. While this evaluation suggests improved outcomes, the service does require refinement. Not all eligible patients on the EAU were admitted to the COPE zone, with more than $50 \%$ of patients with markers of frailty being admitted elsewhere on the EAU. There was always a concern that focusing resources to the COPE zone would be to the detriment of frail patients elsewhere on the EAU, and acknowledging this the COPE MDT is becoming more flexible to increasingly include patients outside the zone. Part of the COPE zones remit was to work alongside acute physicians, sharing specialist skills employed when managing frailty. Reassuringly, patients with markers of frailty admitted into a non-COPE bed in September 2014 had similar outcomes to those in the 2013 cohort.

Four simple markers of frailty were used to guide casefinding of older patients suitable for the COPE zone. Other more comprehensive frailty screening tools were considered, but felt to be too impractical and time consuming in a busy emergency department. These four markers were adapted from recommendations in the Quality care for older people with urgent and emergency care needs 'Silver Book'. Although the addition of other criteria may have helped to prioritise the 'frailest' patients, it was felt these four criteria were adequate as a pragmatic 'screening' tool. The best way to identify frail patients in the acute setting has yet to be firmly established. ${ }^{13,17}$ The main disadvantage of our method was its wide reach, however it has proved easy to implement in clinical practice. This research was not designed in any way to validate these criteria.

\section{Outcome measures}

Rates of direct discharge from the EAU have increased, as well as greater use of community follow-up teams on discharge, and a reduction in discharge rates to higher levels of care. This appears to have been done safely looking at short-term outcomes, and is in line with the current ethos to keep older patients supported in the community where possible. Facilitating rapid discharge of older patients effectively and safely is challenging and despite providing evidence-based CGA to almost half of all patients with markers of frailty, our readmission rates remain stubbornly high (though comparable with current literature) ${ }^{18}$ It is not easy to predict which vulnerable patients will be readmitted given the large overlap of risk factors for rehospitalisation with markers of frailty. ${ }^{19-21}$ While good evidence exists for readmission prevention strategies in specific disease groups, this is not the case when considering frail older patients. ${ }^{22-24}$

Patients with markers of frailty in 2014 had shorter mean lengths of stay. There are two theories for this: one being an effect of increased rates of direct discharge from EAU (as demonstrated), and the second being that earlier CGA input had prevented delays further down the line. This second theory 
is supported by previous research looking at geriatrician input in emergency departments and the preoperative orthopedic setting. ${ }^{8,25}$ However, when we compared patients admitted to the wards who had received early CGA with those who had not, this was not the case, with both groups having a similar length of stay.

\section{Limitations of this study}

It was not possible to perform a clinical trial looking at the impact of the COPE zone given the iterative development of the service. This was a retrospective analysis of case notes, and conclusions should be made with this caveat. Only one month's discharge data has been analysed for each population, and this may not be representative of overall performance throughout the year. Readmission rates were only measured up to 30 days and no longer term outcome data were collected.

No other significant changes to service were made during the time period studied, but potential confounding factors include differences in case mix, and more formalised documentation in 2014 leading to more favorable data collection. This study has not looked at other major prognostic markers such as comorbid conditions, therefore differences in case mix cannot be completely excluded (however note all baseline demographics bar sex ratio are comparable).

At the time of writing we are unaware of similar service configurations in the UK, and thus no comparison with benchmarking data has been made.

\section{Future work/ongoing improvement}

Continuous audit of the COPE zone at SRFT is ongoing to optimise effectiveness. In particular, further analysis is required to try and tease out both predictors of readmissions, and effective remedial strategies. Long-term outcome data are also being collated to assess longevity of effect. We are also interested to look further at the impact of early CGA on outcomes such as rates of inpatient complications. Further planned work includes looking at quality indicators measures such as patient experience questionnaires. Working to a sevenday service is a top priority.

\section{Conclusions}

The introduction of an embedded frailty unit within the EAU at SRFT has allowed resources to be focused on older patients with the greatest need. We have demonstrated how a novel, targeted approach to front-line geriatric services, integrated with and alongside acute medicine, can improve service delivery and access to resources without major investment or impediment of patient flow.

\section{Acknowledgements}

We would like to thank Dr AT Pattison and Dr J Wallace for their invaluable input in developing the COPE zone, and Prof N Pendleton and Dr N Proudlove for advice pertaining to the manuscript.

\section{References}

1 Banerjee J, Conroy S, Cooke MW. Quality care for older people with urgent and emergency care needs in UK emergency departments. Emerg Med J 2013;30:699-700.
2 Society The British Geriatrics. Fit for frailty. Consensus best practice guidance for the care of older people living with frailty in community and outpatient settings. London: British Geriatrics Society, 2014.

3 Baztán JJ, Suárez-García FM, López-Arrieta J et al. Effectiveness of acute geriatric units on functional decline, living at home, and case fatality among older patients admitted to hospital for acute medical disorders: meta-analysis. BMJ 2009;338:b50.

4 Stuck AE, Siu AL, Wieland GD, Rubenstein L, Adams J. Comprehensive geriatric assessment: a meta-analysis of controlled trials. Lancet 1993;342:1032-6.

5 Conroy S, Ferguson C, Woodard J, Banerjee J. Interface geriatrics: evidence-based care for frail older people with medical crises. $\mathrm{Br} \mathrm{J}$ Hosp Med (Lond) 2010;71:98-101.

6 Ellis G, Whitehead MA, O'Neill D, Langhorne P, Robinson D. Comprehensive geriatric assessment for older adults admitted to hospital. Cochrane Database Syst Rev 2011;6:CD006211.

7 Harari D, Martin F, Buttery A, O'Neill S, Hopper A. The older persons' assessment and liaison team 'OPAL': evaluation of comprehensive geriatric assessment in acute medical inpatients. Age Ageing 2007;36:670-5.

8 Conroy SP, Ansari K, Williams M et al. A controlled evaluation of comprehensive geriatric assessment in the emergency department: the 'emergency frailty unit'. Age Ageing 2014;43:109-14.

9 Salvi F, Morichi V, Grilli A et al. Screening for frailty in elderly emergency department patients by using the Identification of Seniors At Risk (ISAR). J Nutr Health Aging 2012;16:313-8.

10 Edmans J, Bradshaw L, Franklin M, Gladman J, Conroy S. Specialist geriatric medical assessment for patients discharged from hospital acute assessment units: randomised controlled trial. $B M J$ 2013;347:f5874.

11 Wyrko Z. Frailty at the front door. Clin Med 2015;15:377-81.

12 Xue Q-L. The frailty syndrome: definition and natural history. Clin Geriatr Med 2011;27:1-15.

13 Rodríguez-Mañas L, Féart C et al. Searching for an operational definition of frailty: a Delphi method based consensus statement. The frailty operative definition-consensus conference project. J Gerontol A Biol Sci Med Sci 2013;68:62-7.

14. Trust SRF. Salford Royal NHS Foundation Trust - annual report and accounts 2013/2014. Salford: Salford Royal NHS Foundation Trust, 2014.

15 Ellis G, Langhorne P. Comprehensive geriatric assessment for older hospital patients. Br Med Bull 2005;71:45-59.

16 Silvester KM, Mohammed MA, Harriman P, Girolami A, Downes TW. Timely care for frail older people referred to hospital improves efficiency and reduces mortality without the need for extra resources. Age Ageing 2014;43:472-7.

17 Sternberg SA, Schwartz AW, Karunananthan S, Bergman H, Mark Clarfield A. The identification of frailty: a systematic literature review. J Am Geriatr Soc 2011;59:2129-38.

18 Department of Health. Emergency readmissions: England 2000-01 to 2010-11. London: DoH, 2013. Available online at www.gov.uk/ government/publications/emergency-readmissions-data [Accessed 12 November 2015].

19 Golden AG, Tewary S, Dang S, Roos BA. Care management's challenges and opportunities to reduce the rapid rehospitalization of frail community-dwelling older adults. Gerontologist 2010;50:451-8.

20 Lanièce I, Couturier P, M Dramé et al. Incidence and main factors associated with early unplanned hospital readmission among French medical inpatients aged 75 and over admitted through emergency units. Age Ageing 2008;37:416-22.

21 Wou F, Gladman JR, Bradshaw L, Franklin M, Edmans J, Conroy SP. The predictive properties of frailty-rating scales in the acute medical unit. Age Ageing 2013;42:776-81.

22 Naylor MD, Brooten DA, Campbell RL et al. Transitional care of older adults hospitalized with heart failure: a randomized, controlled trial. J Am Geriatr Soc 2004;52:675-84 
23 Andersen HE, Schultz-Larsen K, Kreiner S et al. Can readmission after stroke be prevented? Results of a randomized clinical study: a postdischarge follow-up service for stroke survivors. Stroke 2000;31:1038-45.

24 Conroy SP, Stevens T, Parker SG, Gladman JR. A systematic review of comprehensive geriatric assessment to improve outcomes for frail older people being rapidly discharged from acute hospital: 'interface geriatrics'. Age Ageing 2011;40:436-43.
25 Leung AH-C, Lam T-P, Cheung W-H et al. An orthogeriatric collaborative intervention program for fragility fractures: a retrospective cohort study. J Trauma 2011;71:1390-4.

Address for correspondence: Dr J Taylor, Department for Ageing and Complex Medicine, Salford Royal NHS Foundation Trust, Salford M6 8HD, UK

Email: joanne.taylor111@gmail.com

\section{Royal College of Physicians Museum and Medicinal Garden}

Visit the Royal College of Physicians (RCP) and discover 500 years of medical history in an acclaimed architectural setting.

The RCP is the oldest medical college in England, and since its foundation in 1518 it has built up magnificent collections of books, manuscripts, portraits, silver, and medical artefacts.

Our celebrated Grade I listed headquarters in Regent's Park is the creation of British architect Sir Denys Lasdun and our garden contains over 1,300 plants, each used as medicine around the world over the past 3,000 years.

\section{Guided tours}

We offer guided tours of the building and garden, and welcome bookings for groups of six or more. Refreshments can be booked and tours tailored for special interest groups. Guided tour charges are $£ 5$ per person (refreshments extra).

\section{Royal College of Physicians, 11 St Andrews Place,} Regent's Park, London NW1 $4 \mathrm{LE}$. Open: Monday- Friday, $9 \mathrm{am}-5 \mathrm{pm}$, free entry

Library, Archive and Museum Services

Tel: +44 (0)203075 1543

Email: history@rcplondon.ac.uk

\section{Free entry}

\section{Royal College} of Physicians

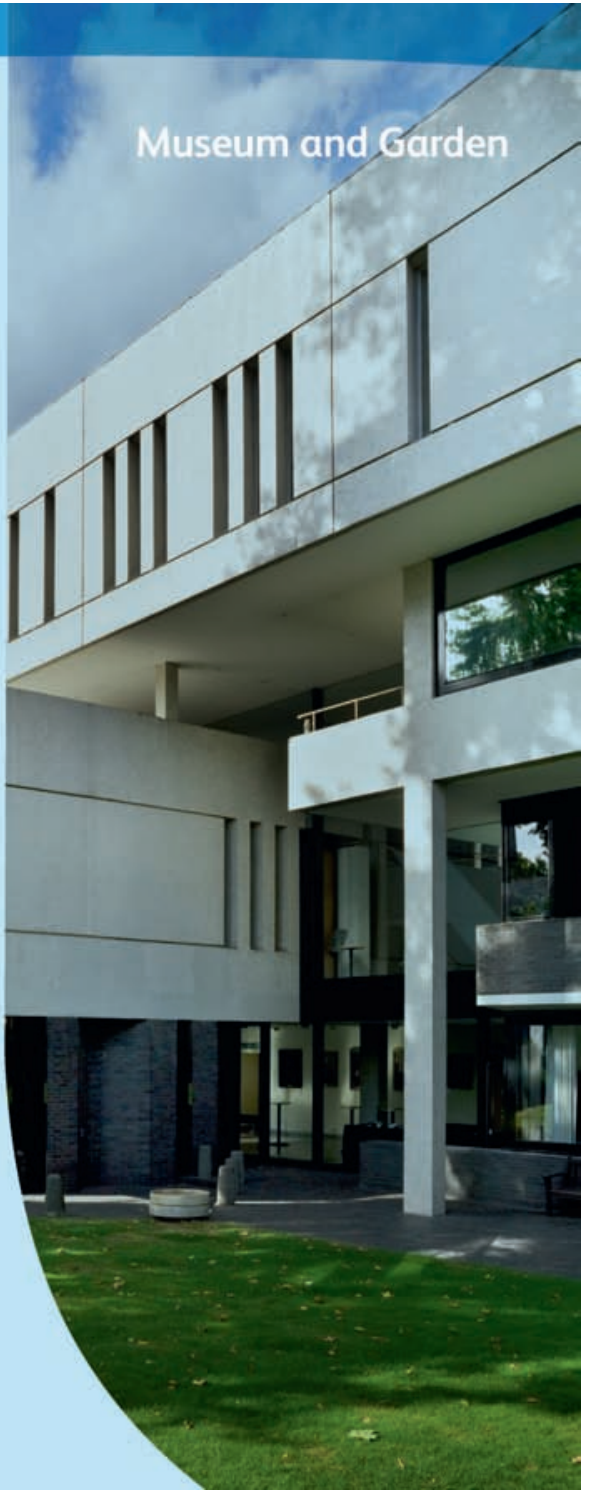

